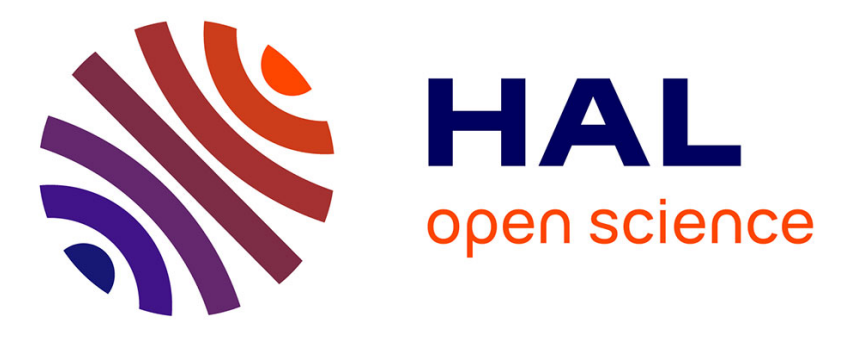

\title{
Service-Oriented and Cloud Computing
}

\author{
Antonio Brogi, Wolf Zimmermann, Kyriakos Kritikos
}

\section{To cite this version:}

Antonio Brogi, Wolf Zimmermann, Kyriakos Kritikos. Service-Oriented and Cloud Computing: 8th IFIP WG 2.14 European Conference, ESOCC 2020, Heraklion, Crete, Greece, September 28-30, 2020, Proceedings. Springer International Publishing, LNCS-12054, 2020, Lecture Notes in Computer Science, 978-3-030-44768-7. 10.1007/978-3-030-44769-4 . hal-03203229

\section{HAL Id: hal-03203229 \\ https:/ /hal.inria.fr/hal-03203229}

Submitted on 21 Apr 2021

HAL is a multi-disciplinary open access archive for the deposit and dissemination of scientific research documents, whether they are published or not. The documents may come from teaching and research institutions in France or abroad, or from public or private research centers.
L'archive ouverte pluridisciplinaire HAL, est destinée au dépôt et à la diffusion de documents scientifiques de niveau recherche, publiés ou non, émanant des établissements d'enseignement et de recherche français ou étrangers, des laboratoires publics ou privés.

\section{(c)(1)}

Distributed under a Creative Commons Attribution| 4.0 International License 


\section{Lecture Notes in Computer Science}

Founding Editors

Gerhard Goos

Karlsruhe Institute of Technology, Karlsruhe, Germany

Juris Hartmanis

Cornell University, Ithaca, NY, USA

Editorial Board Members

Elisa Bertino

Purdue University, West Lafayette, IN, USA

Wen Gao

Peking University, Beijing, China

Bernhard Steffen (1)

TU Dortmund University, Dortmund, Germany

Gerhard Woeginger (1)

RWTH Aachen, Aachen, Germany

Moti Yung

Columbia University, New York, NY, USA 
More information about this series at http://www.springer.com/series/7408 
Antonio Brogi · Wolf Zimmermann ·

Kyriakos Kritikos (Eds.)

\section{Service-Oriented and Cloud Computing}

8th IFIP WG 2.14 European Conference, ESOCC 2020 Heraklion, Crete, Greece, September 28-30, 2020 Proceedings 


\section{Editors}

Antonio Brogi (D)

Università di Pisa

Pisa, Italy

Kyriakos Kritikos (iD)

University of the Aegean

Karlovasi, Greece

\author{
Wolf Zimmermann \\ Martin-Luther-Universität Halle-Wittenberg \\ Halle (Saale), Germany
}

ISSN $0302-9743 \quad$ ISSN 1611-3349 (electronic)
Lecture Notes in Computer Science
ISBN 978-3-030-44768-7 $\quad$ ISBN 978-3-030-44769-4 (eBook)
https://doi.org/10.1007/978-3-030-44769-4

LNCS Sublibrary: SL2 - Programming and Software Engineering

(C) IFIP International Federation for Information Processing 2020

The chapters "Identification of Comparison Key Elements and Their Relationships for Cloud Service Selection" and "Technology-Agnostic Declarative Deployment Automation of Cloud Applications" are licensed under the terms of the Creative Commons Attribution 4.0 International License (http:// creativecommons.org/licenses/by/4.0/). For further details see license information in the chapters.

This work is subject to copyright. All rights are reserved by the Publisher, whether the whole or part of the material is concerned, specifically the rights of translation, reprinting, reuse of illustrations, recitation, broadcasting, reproduction on microfilms or in any other physical way, and transmission or information storage and retrieval, electronic adaptation, computer software, or by similar or dissimilar methodology now known or hereafter developed.

The use of general descriptive names, registered names, trademarks, service marks, etc. in this publication does not imply, even in the absence of a specific statement, that such names are exempt from the relevant protective laws and regulations and therefore free for general use.

The publisher, the authors and the editors are safe to assume that the advice and information in this book are believed to be true and accurate at the date of publication. Neither the publisher nor the authors or the editors give a warranty, expressed or implied, with respect to the material contained herein or for any errors or omissions that may have been made. The publisher remains neutral with regard to jurisdictional claims in published maps and institutional affiliations.

This Springer imprint is published by the registered company Springer Nature Switzerland AG The registered company address is: Gewerbestrasse 11, 6330 Cham, Switzerland 


\section{Preface}

Service-oriented and cloud computing have made a huge impact both on the software industry and on the research community. Today, service and cloud technologies are applied to build large-scale software landscapes as well as to provide single software services to end users. Services today are independently developed and deployed as well as freely composed while they can be implemented in a variety of technologies, quite an important fact from a business perspective. Similarly, cloud computing aims at enabling flexibility by offering a centralized sharing of resources. The industry's need for agile and flexible software and IT systems has made cloud computing the dominating paradigm for provisioning computational resources in a scalable, on-demand fashion. Nevertheless, service developers, providers, and integrators still need to create methods, tools, and techniques to support cost-effective and secure development as well as the use of dependable devices, platforms, services, and service-oriented applications in the cloud.

The European Conference on Service-Oriented and Cloud Computing (ESOCC) is the premier conference on advances in the state of the art and practice of service-oriented computing and cloud computing in Europe. The main objectives of this conference are to facilitate the exchange between researchers and practitioners in the areas of service-oriented computing and cloud computing, as well as to explore the new trends in those areas and foster future collaborations in Europe and beyond. The 8th edition of ESOCC, ESOCC 2020, was held in the city of Heraklion in Crete, Greece, during September 28-30, 2020, under the auspices of FORTH-ICS.

ESOCC 2020 was a multi-event conference aimed to cover both an academic and industrial audience. The main event was associated with the main research track, which focused on the presentation of cutting-edge research in both the service-oriented and cloud computing areas. In conjunction, an industrial track was also held bringing together academia and industry by showcasing the application of service-oriented and cloud computing research, especially in the form of case studies, from industry. Overall, 20 submissions were received, out of which 6 outstanding full and 8 short papers were accepted.

Each submission was peer-reviewed by three main reviewers, either directly from the PC members or their colleagues. Due to the high quality of the manuscripts received, additional discussions were conducted, both among the PC members as well as between the two PC chairs, before the final selection was performed. The PC chairs would like to thank all the reviewers that participated in the reviewing process not only for enabling to increase the quality of the received manuscripts but also for sharing particular ideas on how the respective work, even if rejected in its current form in the ESOCC conference, could be substantially improved.

The attendees of ESOCC had the opportunity to follow two outstanding keynotes that were part of the conference program. The first keynote was conducted by Massimo Villari, Professor and Rector Delegate for ICT as well as Head of the Computer Science 
School in the University of Messina, Italy. This keynote concerned recent research advances and trends towards realizing the vision of Osmotic Computing. The second keynote was conducted by Joseph Spillner, Head of the Service Prototyping Lab and Associate Professor at Zurich University of Applied Sciences in Switzerland. This second keynote concerned the presentation of methods for developing production-ready, Function-as-a-Service applications concentrating on scalable event-driven data processing that are well-suited for highly dynamic environments with varying loads.

The additional events held in ESOCC 2020 included the PhD symposium, enabling $\mathrm{PhD}$ students to present their work in front of real experts, as well as the EU projects track, supplying researchers with the opportunity to present the main research results that they have achieved in the context of currently operating EU projects. Further, ESOCC 2020 included the organization of satellite workshops. All these events were accompanied by respective proceedings which were published separately.

Finally, this 8th edition of ESOCC included a novel track dedicated to the conduction of tutorials. This enabled the workshop participants to get acquainted with the latest results of specific European projects as well as of specific European research groups in a practical manner which included demonstrations of research prototypes.

The PC chairs and the general chair would like to gratefully thank all the persons involved in making ESOCC 2020 a success. This includes both the PC members and their colleagues that assisted in the reviews as well as the organizers of the industry track, the PhD symposium, the EU projects track, and the workshops. A special applause should also go to the members of the Local Organizing Committee for their devotion, willingness, and hospitality. Finally, a special thanks goes to all the authors of all the manuscripts submitted to ESOCC 2020, the presenters of the accepted papers who made interesting and fascinating presentations of their work, as well as the active attendees of the conference who initiated interesting discussions and gave fruitful feedback to the presenters. All these persons not only enabled a very successful organization and execution of ESOCC 2020, but also formulate an active and vibrant community which continuously contributes to the research in service-oriented and cloud computing. This also encourages ESOCC to continue contributing with new research outcomes to further facilitate and enlarge its community as well as have a greater impact and share in both the service-oriented and cloud computing research.

September 2020

Antonio Brogi

Wolf Zimmermann

Kyriakos Kritikos 


\section{Organization}

ESOCC 2020 was organized by FORTH-ICS, Greece.

\section{Organizing Committee}

\section{General Chair}

Kyriakos Kritikos

FORTH-ICS and University of the Aegean, Greece

\section{Program Chairs}

Antonio Brogi

Wolf Zimmermann

University of Pisa, Italy

Martin Luther University Halle-Wittenberg, Germany

\section{Industry Track Chair}

Marco Aiello

University of Stuttgart, Germany

\section{Workshop Chairs}

Christian Zirpins

Iraklis Paraskakis

University of Applied Sciences Karlsruhe, Germany

City College, Greece

\section{EU Project Space Chairs}

Pierluigi Plebani

Politecnico di Milano, Italy

Giuliano Casale

Imperial College, UK

\section{PhD Symposium Chairs}

Jacopo Soldani

University of Pisa, Italy

Massimo Villari

University of Messina, Italy

\section{Steering Committee}

Antonio Brogi

Schahram Dustdar

Paul Grefen

Winfried Lamersdorf

Frank Leymann

Flavio de Paoli

Cesare Pautasso

Ernesto Pimentel

Pierluigi Plebani

Ulf Schreier

Massimo Villari
University of Pisa, Italy

TU Wien, Austria

Eindhoven University of Technology, The Netherlands

University of Hamburg, Germany

University of Stuttgart, Germany

University of Milano-Bicocca, Italy

University of Lugano, Switzerland

University of Malaga, Spain

Politecnico di Milano, Italy

Hochschule Furtwangen University, Germany

University of Messina, Italy 
John Erik Wittern

Olaf Zimmermann

Wolf Zimmermann

\section{Program Committee}

Marco Aiello

Vasilios Andrikopoulos

Farhad Arbab

Luciano Baresi

Giuliano Casale

Marco Comuzzi

Schahram Dustdar

Robert Engel

Rik Eshuis

Ilche Georgievski

Paul Grefen

Thomas Gschwind

Martin Henkel

Einar Broch Johnsen

Ernoe Kovacs

Patricia Lago

Winfried Lamersdorf

Kung-Kiu Lau

Welf Loewe

Zoltan Adam Mann

Guadalupe Ortiz

Claus Pahl

Iraklis Paraskakis

Ernesto Pimentel

Pierluigi Plebani

Dumitru Roman

Ulf Schreier

Stefan Schulte

Jacopo Soldani

Massimo Villari

Mandy Weissbach

Stefan Wesner

Robert Woitsch

Gianluigi Zavattaro

Christian Zirpins
IBM T. J. Watson Research Center, USA

HSR FHO Rapperswil, Switzerland

Martin Luther University Halle-Wittenberg, Germany
University of Groningen, The Netherlands

University of Groningen, The Netherlands

CWI, The Netherlands

Politecnico di Milano, Italy

Imperial College, UK

Ulsan National Institute of Science and Technology, South Korea

TU Wien, Austria

IBM Almaden, USA

Eindhoven University of Technology, The Netherlands University of Groningen, The Netherlands

Eindhoven University of Technology, The Netherlands

IBM Zurich Research Lab, Switzerland

Stockholm University, Sweden

University of Oslo, Norway

NEC Europe Network Labs, Germany

VU University Amsterdam, The Netherlands

University of Hamburg, Germany

The University of Manchester, UK

Linnaeus University, Sweden

University of Duisburg-Essen, Germany

University of Cadiz, Spain

Free University of Bozen-Bolzano, Italy

City College, Greece

University of Malaga, Spain

Politecnico di Milano, Italy

Sintef, Norway

University of Applied Sciences Furtwangen, Germany

TU Wien, Austria

University of Pisa, Italy

University of Messina, Italy

Martin Luther University Halle-Wittenberg, Germany

University of Ulm, Germany

BOC Asset Management, Germany

University of Bologna, Italy

University of Applied Sciences Karlsruhe, Germany 


\section{Contents}

\section{Formal Methods}

Testing Conformance in Multi-component Enterprise Application

Management. . . . . . . . . . . . . . . . . . . . . . . .

Jacopo Soldani, Lars Luthmann, Malte Lochau, and Antonio Brogi

Formalizing Event-Driven Behavior of Serverless Applications . . . . . . . . .

Matthew Obetz, Anirban Das, Timothy Castiglia, Stacy Patterson, and Ana Milanova

Probabilistic Verification of Outsourced Computation Based on Novel Reversible PUFs . . . . . . . . . . . . . . . . . . . . . . . . . . .

Hala Hamadeh, Abdallah Almomani, and Akhilesh Tyagi

\section{Cloud Service and Platform Selection}

Multiplayer Game Backends: A Comparison of Commodity

Cloud-Based Approaches . . . . . . . . . . . . . . . . . . . . . . .

Nicos Kasenides and Nearchos Paspallis

Are Cloud Platforms Ready for Multi-cloud? . . . . . . . . . . . . . 56

Kyriakos Kritikos, Pawet Skrzypek, and Feroz Zahid

Identification of Comparison Key Elements and Their Relationships

for Cloud Service Selection . . . . . . . . . . . . . . . . . . . . . .

Anis Ahmed Nacer, Olivier Perrin, and François Charoy

\section{Deployment and Workflows}

Deployable Self-contained Workflow Models . . . . . . . . . . . . . . . . . .

Benjamin Weder, Uwe Breitenbücher, Kálmán Képes, Frank Leymann, and Michael Zimmermann

Technology-Agnostic Declarative Deployment Automation of Cloud Applications . . . . . . . . . . . . . . . . . . . .

Michael Wurster, Uwe Breitenbücher, Antonio Brogi, Lukas Harzenetter, Frank Leymann, and Jacopo Soldani

Blockchain-Based Healthcare Workflows in Federated Hospital Clouds . . . . . Armando Ruggeri, Maria Fazio, Antonio Celesti, and Massimo Villari 


\section{Monitoring}

Monitoring Behavioral Compliance with Architectural Patterns

Based on Complex Event Processing . . . . . . . . . . . . . . . . . .

Christoph Krieger, Uwe Breitenbücher, Michael Falkenthal,

Frank Leymann, Vladimir Yussupov, and Uwe Zdun

Towards Real-Time Monitoring of Data Centers Using Edge Computing . . . .

Brian Setz and Marco Aiello

Modeling Users' Performance: Predictive Analytics in an IoT Cloud

Monitoring System . . . . . . . . . . . . . . . . . . . . . . . . . . . . 149

Rosa Di Salvo, Antonino Galletta, Orlando Marco Belcore, and Massimo Villari

\section{Data Distribution and Analytics}

Multi-source Distributed System Data for AI-Powered Analytics. . . . . . . . . 161 Sasho Nedelkoski, Jasmin Bogatinovski, Ajay Kumar Mandapati, Soeren Becker, Jorge Cardoso, and Odej Kao

Blockchain- and IPFS-Based Data Distribution for the Internet of Things. . . . Simon Krejci, Marten Sigwart, and Stefan Schulte 